UNIVERSITY
OF DEBRECEN

FACULTY OF

HEALTH

NYÍREGYHÁZA

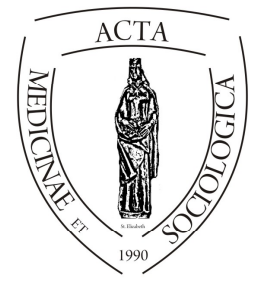

ACTA

MedSoC

VOLUMe 3.

2013

\title{
The nurse and conceptual model in practice
}

\author{
Pavel Scholz, Valérie Tóthová, František Dolák \\ University of South Bohemia in České Budějovice, Faculty of Health and Social \\ Studies, Department of Nursing and Midwifery
}

\begin{abstract}
Summary. The authors of the article present the results of quantitative research focused on the nurses' opinions on conceptual models. The research constitutes a part of the results of the GAJU 079/2010/ grant project denominated: Use of the conceptual model and classification systems in nursing documentation, implemented at ZSF JU. The nursing documentation includes conceptual models. The conceptual model is a developing and changing arrangement of thinking and nursing activity, reflecting the attitudes, methods and goals of nursing. The goal of this article is to point out the current knowledge of nurses from hospital facilities in the area of conceptual models. Another partial goal consists of ascertainment of the nurses' interest in education in the area of conceptual models. The strategy of quantitative research investigation with the help of questionnaire technology was used to process these issues. The research investigation was implemented in hospital facilities of South Bohemian Region. The implementation took place in selected standard wards and intensive care wards of the region. The nurses working at such wards acted as respondents. The questionnaire was segmented into 5 parts: identification data, section dealing with the use of nursing documentation and section focused on classification systems, section of conceptual models and multicultural issues. This article focuses on the most interesting results of the nurses' opinions on the conceptual models, including the model application in practice, as well as on the nurses' interest in education in this area. The total number of questionnaires used for analysis was 565 . Almost $40 \%$ of the nurses stated that they use the procedures from conceptual models in practice. The fact whether nurses use the procedures is related to the duration
\end{abstract}


of their work experience. Nurses with shorter work experience use them more frequently while nurses with the longest work experience use the procedures the least frequently. The results also show the lack of the nurses' interest in educational courses in the area of conceptual models.

Key words: nurse, conceptual models, knowledge, model application

\section{Intruduction}

The development of nursing is considered one of the essential tasks of current nursing by a lot of nurses.

Nursing at its beginnings was based mainly on natural and behavioural sciences.

The 20th century shows the use of biomedical model of nursing patients. The patient was expected to adapt to the rules of the health care workers. By the end of the 20th century, a new nursing philosophy was developed and the human in health and in disease, understood as a whole, became the subject of nursing. Nursing is a continuously developing profession and nowadays it is deeply focused on its own unique knowledge base. On the conference on the development of nursing, the Johnson, Reilly and Roy group termed different views on nursing explicitly as conceptual models. The term and further development of conceptual models can be considered an essential step towards the establishment of an independent scientific discipline, nursing (Sedláková and Kalátová, 2010). The identification and development of the knowledge base consists in the cognition and use of conceptual models in practice and in research. The integration of conceptual models into the nurses' education and their application in practice constitutes a distinctive progress leading to the increase of nursing care (Walsh, 2007). The creation of conceptual models and their terming as such was a very important progress in the nursing discipline. The nursing conceptual model is not a theory given once and for all but a developing and changing way of arrangement of thinking and nursing activity, reflecting the attitudes, methods and goals of nursing (Archalousová and Slezáková, 2007). In current nursing, we usually interpret the theories and models created by American nurses because we still do not have our specific models (Sedláková a Kalátová, 2010). Every health care facility is obliged by law to keep health care documentation of the patients, including nursing documentation. Thus the nurses' and midwives' activity shifts to a more controllable level. The requirements imposed on it are considerable because it must be as easy to complete as possible, and at the same time accurate and comprehensive. The nursing documentation prepared by using conceptual 
models can help to collect the nurse's anamnesis from the patient and the patient's family, to identify the nursing problem, to plan the care for the patient and, of course, to implement it (Pavlíková, 2006).

\section{Goal}

One of the goals of this article is to point out the current knowledge of nurses on hospital facilities in the area of conceptual models and further to point out the nurses' interest in education in the area of conceptual models.

\section{Methodology}

The strategy of quantitative research with the help of questionnaire technology was used to process these issues. The research investigation was implemented in cooperation with hospital facilities of South Bohemian Region: Hospital of České Budějovice a.s., Hospital of Písek a.s., Hospital of Tábor a.s.,

Hospital of Jindřichův Hradec, a.s., Hospital of Český Krumlov, a.s., Hospital of Strakonice, a.s., and Hospital of Prachatice, a.s. The research investigation was performed at selected standard wards and intensive care wards; the nurses working at those wards acted as respondents. The questionnaire was anonymous and included 59 questions. The questionnaire was segmented into 5 parts: identification data, section dealing with the use of nursing documentation and section focused on NIC and NOC classification systems, section of conceptual models and multicultural issues. The nurses' opinions on the conceptual models, including the model application in practice, as well as the nurses' interest in education in this area were ascertained. The total number of distributed questionnaires amounted to 750. Finally 565 fully submitted questionnaires were used for subsequent analysis, which constitutes $75 \%$ return. The data were processed through the SASD (Statistic analysis of social data) software, version 1.4.4. 


\section{Selected results}

As we show in Diagram No. 1, more than a half (52.0\%) of the nurses answered "yes" or "rather yes" to the question whether they knew the concept of "conceptual models in nursing". Negative standpoint was chosen by $36.2 \%$ nurses; the remaining $11.8 \%$ chose the answer "I don't know".

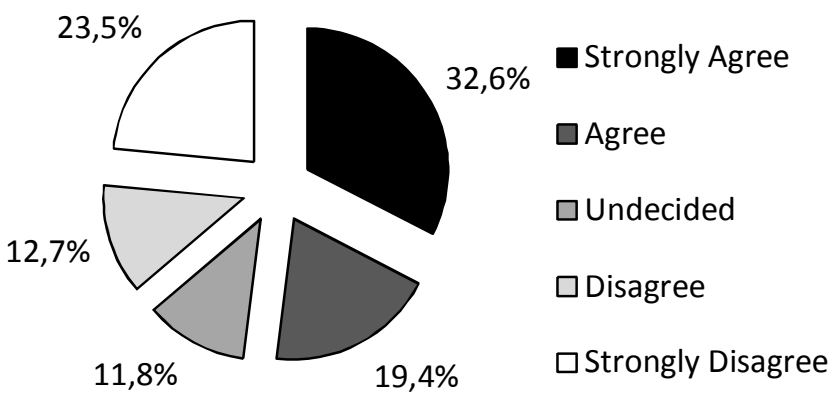

Diagram No. 1

Knowledge of the concept of "conceptual models in nursing"(in \%) $\mathrm{N}=561$

The analyses based on the second degree of classification demonstrated that the knowledge of the concept of "conceptual models in nursing" is significantly influenced by a number of factors. The results also show that nurses with shorter work experience (up to 10 years) have more knowledge in this area while nurses with longer work experience have less knowledge. Also the influence of education is statistically significant. Higher knowledge is reported by nurses with advanced vocational education (VOŠ) and particularly with university education (VŠ); lower knowledge is reported by graduates from secondary schools of nursing (SZŠ) and by nurses with postgraduate education. There was also a distinctive tendency showing that the knowledge of the concept of "conceptual models in nursing" is reported more by younger nurses while less by older ones. 


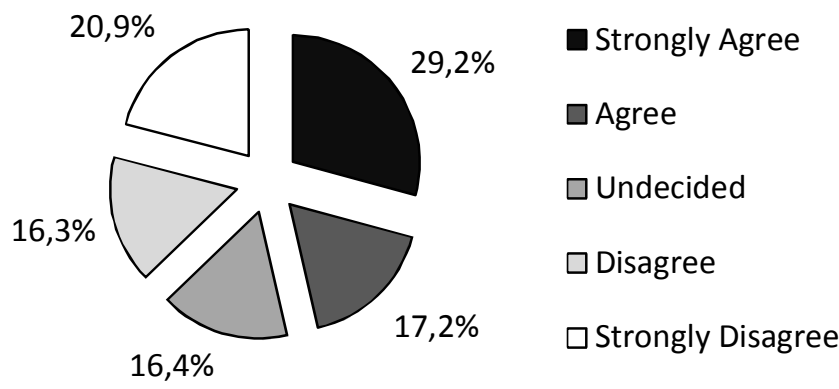

Diagram No. 2

Encounter with a specific conceptual model in the course of education (in \%) $\mathrm{N}=559$

Another area, on which the attention of the researchers was focused, consisted of the fact whether the nurses had encountered a specific conceptual model in the course of their education. The question was asked as close-ended question with a standardized five-degree scale of answers. A total number of $46.4 \%$ of nurses (sum of "yes" and "rather yes" answers) had encountered some conceptual model in the course of their education. The question was answered negatively by $37.2 \%$ of the nurses while the remaining $16.4 \%$ chose the answer "I don't know". It means that a greater part of nurses state that they rather or definitely encountered some conceptual model in the course of their education. But at present, the nurses who state that have not encountered a specific model or who do not know about it slightly prevail. Nurses from the hospitals of České Budějovice, Písek and Strakonice significantly more frequently encountered a specific conceptual model in the course of their education, whereas nurses from the hospitals of Jindrichův Hradec and Prachatice encountered it less frequently. Nurses with shorter work experience (up to 10 years) significantly more frequently encountered a specific comprehensive model in the course of their education while nurses with longer work experience report on a significantly fewer frequency. Education has also considerably influenced this fact. Nurses with VOŠ and VŠ education significantly more frequently encountered a specific conceptual model in the course of their education while nurses with SZŠS and with postgraduate education encountered it less frequently. In addition, a tendency among younger nurses having encountered a specific conceptual model in the course of their education more frequently than older nurses can also be recognized. (Diagram No.2) 
As we show in Diagram No. 3, more than half (57.5\%) of the nurses answers "rather yes" or "yes" to the question whether they have encountered Marjory Gordon's conceptual model. Less than one third $(29.0 \%)$ of the nurses answers the question negatively while the remaining $13.5 \%$ chooses the answer "I don't know". Thus the conclusion which can be reached is that most nurses at the hospitals of South Bohemian Region have already encountered Marjory Gordon's conceptual model. The low number of observations and their distribution in the individual fields of the contingency charts did not allow applying tests of statistic significance without correction.

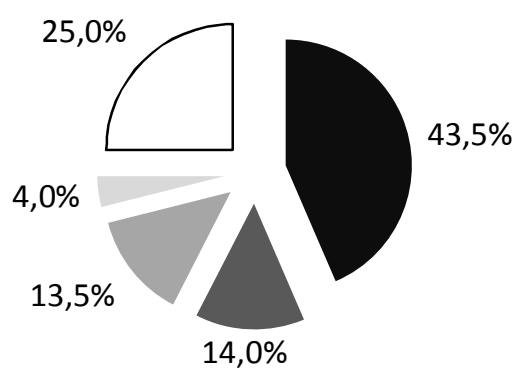

- Strongly Agree

Agree

- Undecided

Disagree

$\square$ Strongly Disagree

Diagram No. 3

Encounter with Marjory Gordon's conceptual model (in \%) N =556

Nevertheless, strong tendencies can be observed that nurses from the hospitals of České Budějovice and Strakonice encountered the model the most frequently while the nurses from the hospitals of Jindřichův Hradec and in Prachatice encountered it the least frequently. It also turned out that nurses with shorter work experience, younger nurses and nurses graduated from VOŠ or VŠ encountered the model more frequently.

Almost 2/5 (39.4\%) of the nurses of the hospitals of South Bohemian Region stated that they rather or definitely used some procedures from the conceptual models in their practice. More than a quarter (27.6\%) of the nurses are not able to assess the fact and choose the answer "I don't know"; the remaining ones, up to one third (33.0\%) states that they rather or definitely do not use such procedures in their practice. Thus it can be stated that nurses who admit the use of some procedures from the conceptual models in their practice is slightly prevail among nurses from the hospitals of South Bohemian Region. 


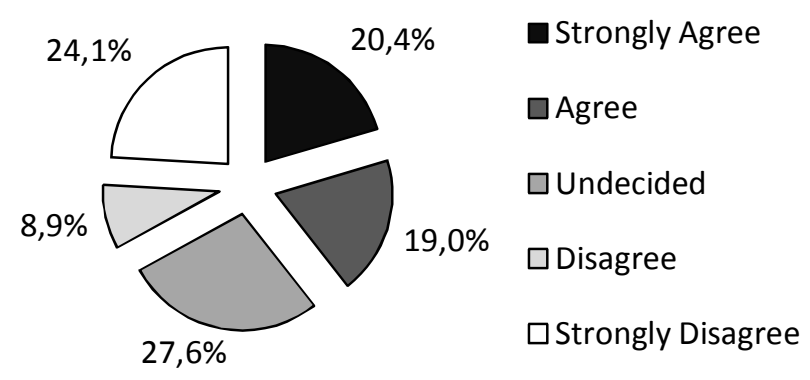

Diagram No. 4

Use of procedures from conceptual models in practice (in \%) $\mathrm{N}=564$

Statistically significant differences in the answers to this question were identified among the nurses from individual hospitals. Some procedures from the conceptual models are used in practice particularly by the nurses from the hospitals of Strakonice and České Budějovice, while nurses from the hospital of Prachatice use them significantly less. The fact whether nurses use the procedures is also related to the duration of their work experience. Nurses with shorter work experience use them more frequently; nurses with the longest work experience use the procedures less frequently. It was also definitely demonstrated that nurses with VOŠ and VŠ education use the procedures significantly more frequently while nurses with SZŠ answer "do not know" more frequently than the others and nurses with postgraduate education use the procedures less frequently. (Diagram No. 4)

The nurses who stated the use of some procedures from the conceptual models in their practice (answers "yes" and "rather yes") were further asked some closeended and filtered questions to map whether they consider having sufficient information on the conceptual models in nursing. As we show in Diagram No. 5, only about $1 / 10(10.8 \%)$ of the nurses considers having sufficient information on the conceptual models in nursing. Up to $2 / 3$ of them $(67.3 \%)$ considers not having sufficient information and the remaining $21.9 \%$ is not able to assess the question and chooses the answer "I don't know". Thus it can be stated that the prevailing majority of nurses from the hospitals of South Bohemian Region considers not having sufficient information on the conceptual models in nursing. Tests of statistical significance could not be applied in this case due to the low number of observations (filtered question). But the comparison of relative frequencies suggests that the distribution found in the whole set also applies in its individual parts segmented by socio-demographic features. 


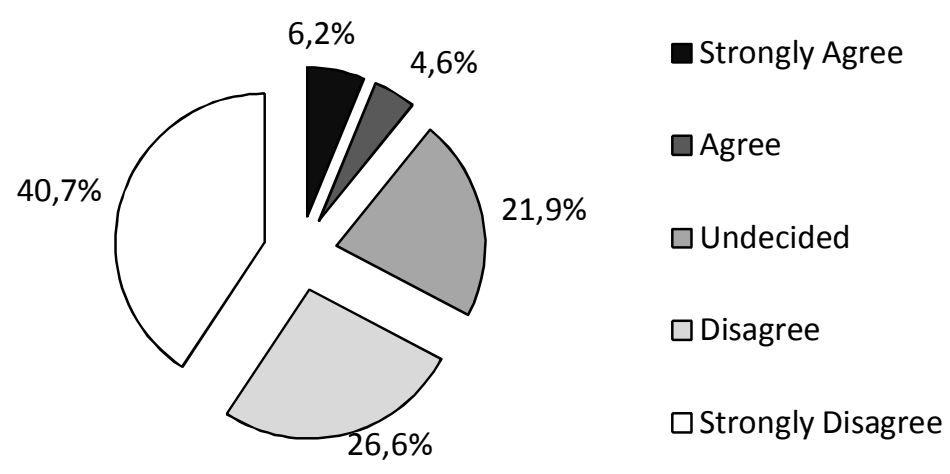

Diagram No. 5

Sufficient information on conceptual models in nursing FILTER (in \%) N = 324

As we show in Diagram No. 6, the results suggest that almost a half (46.4\%) of the nurses are not able to assess whether the system of care practiced in their wards is suitable for nursing documentation prepared according to the conceptual model. About 1/3 (32.5\%) of the nurses think that their system is suitable; the remaining $21.0 \%$ thinks that it is not suitable. So the conclusion which can be reached is that for most of the nurses this question is not clear and that they cannot assess the suitability of the conceptual model for nursing documentation in their wards. The analysis is based on the second degree of classification demonstrating statistically significant deviations in the nurses' opinions on this issue in hospitals of South Bohemian Region. Nurses from the hospital of Strakonice are absolutely convinced about the suitability of the conceptual model for nursing documentation in the wards where they work; the nurses from the hospitals of České Budějovice and Prachatice are the least convinced; particularly the nurses from the hospital of Jindrichův Hradec are not able to take an unambiguous stand.

It shows that the opinions on this question differ significantly among the nurses at the observed hospitals. Nurses working at standard wards are more likely to use the conceptual model while nurses from the intensive care units take a negative stand more frequently. Thus the nurses' standpoint to this issue is conditioned by the type of ward they work in. The opinion on this issue is also conditioned by the duration of work experience - the longer the nurses' work experience, the more uncertain is their standpoint and the more frequent the answer "I don't know" is. It was also demonstrated that the opinion on the 
possibility of using the conceptual model for nursing documentation is conditioned by education.

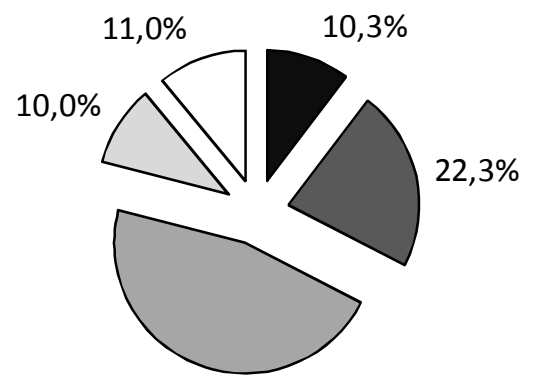

$46,4 \%$ $\square$ Strongly Agree

$\square$ Agree

$\square$ Undecided

$\square$ Disagree

$\square$ Strongly Disagree

Diagram No. 6

System of care of the respondents' workplace and its suitability for nursing documentation prepared according to the conceptual model (in \%) $\mathrm{N}=562$

Mainly nurses with university education prefer this possibility while nurses with SZŠ and postgraduate education more frequently state "I don't know". Thus it can be stated that the standpoint to this issue is conditioned by the type of facility and the type of ward the nurse works in, as well as by the duration of her work experience and by the degree of the education achieved.

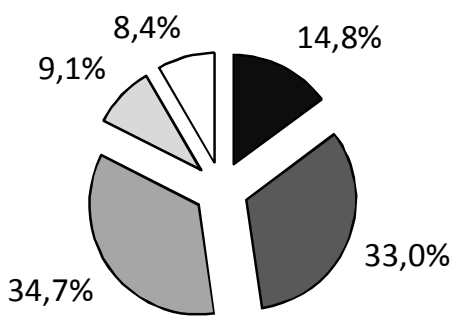

\author{
Strongly Agree \\ $\square$ Agree \\ $\square$ Undecided \\ $\square$ Disagree \\ $\square$ Strongly Disagree
}

S

Diagram No. 7

Nurses' opinion on the use of one conceptual model within nursing documentation (in \%) $\mathrm{N}=561$ 
As we can in Diagram No. 7, 47.8\% of the nurses working in the hospitals of South Bohemian Region would welcome the use of one conceptual model within the nursing documentation. Negative stand to this thesis was taken by $17.5 \%$ and the remaining $34.7 \%$ do not have a clear opinion on this issue and chose the answer "I don't know". Thus most nurses prefer the use of one conceptual model within the nursing documentation. The standpoint to this issue differs by the health care facility the nurse works in. One conceptual model is preferred particularly by the nurses at Strakonice and Písek who have more decisive opinion on this issue than the nurses at the other hospitals. The latter one more frequently state "I don't know". That means that the opinions on this question differ significantly among the nurses from the observed hospitals. Nurses with shorter work experience prefer the use of one conceptual model in nursing documentation, while nurses with longer work experience more frequently do not have a clear opinion on this issue. It was also seen that the use of one conceptual model within the nursing documentation is particularly preferred by nurses with university education while nurses with SZŠ and postgraduate education do not have a clear opinion and choose the answer "I don't know" more frequently.

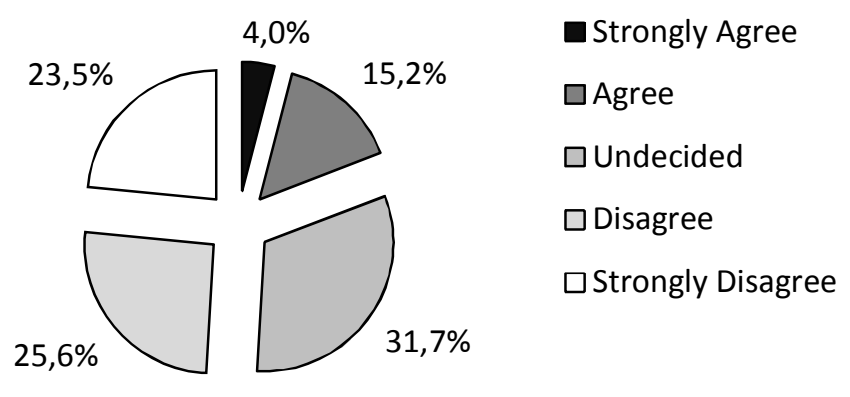

Diagram No. 8

Nurses' opinion on the use of multiple conceptual models within nursing documentation (in \%) $\mathrm{N}=558$

As we show in Diagram No. 8, the analysis of the results shows that $19.2 \%$ of the respondents expressed their consent with the use of multiple conceptual models within nursing documentation while $49.1 \%$ of the nurses are against such procedure and the remaining $31.7 \%$ do not have a clear opinion on this issue. So it was confirmed that those who prefer the use of one conceptual model do not agree with the use of multiple conceptual models and vice versa. 


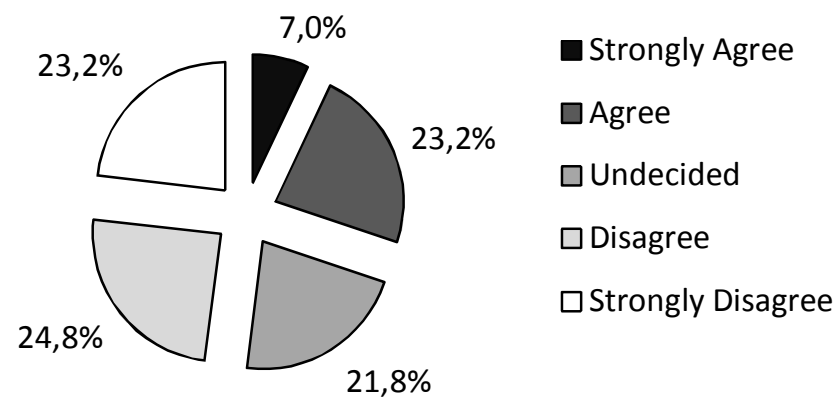

\footnotetext{
Diagram No. 9

Respondents' interest in educational courses in the area of conceptual models (in \%) $\mathrm{N}=560$
}

The last part of the research, the area of conceptual models, was focused on the issue of education.

It was ascertained whether the nurses from the hospitals of South Bohemian Region were interested in educational courses in the area of conceptual models. The analysis shows that at present, lack of interest in a possible course on the area of conceptual models prevails among the nurses from the hospitals of South Bohemian Region. Almost one half of the nurses (48.0\%) expressed such lack of interest. About 3/10 (30.2\%) of the nurses expressed their interest while for the remaining $1 / 5(21.8 \%)$ the question was not clear and chose the answer "I don't know". The simple comparison of relative frequencies shows that nurses from the hospital of Strakonice showed the highest interest in educational courses. But tests of significance cannot be applied due to the low number of observations in extreme scale values. Nurses with medium duration of work experience show more interest while nurses with the shortest and the longest work experience in their branch are less interested. Other statistically significant context was not identified. (Diagram No. 9) 


\section{Discussion}

One of the goals of the research consisted of ascertaining the level of information of the nurses on the conceptual models in nursing. The area of knowledge shows interesting findings that nurses with VOŠ and particularly with VŠ report higher knowledge of the concept of nursing conceptual model while the graduates of SZS and nurses with postgraduate education report on lower knowledge. This result may be related to the fact that the study programs ranging from advanced vocational schools to Bachelor and Master Degrees at universities include subjects dealing with the conceptual model. We can base our statement on the results presented in Diagram 3. M. Gordon's conceptual model is quite well known among the nursing staff and it ranks among the basic conceptual models (Parker, 2001). In connection with that fact, we wanted to ascertain whether the respondents knew this concept. The analysis of the results confirms our assumption that M. Gordon's conceptual model is known to the nurses. The results show that the information about the model has mainly been passed in recent years at the level of advanced schools of nursing and universities. The practical use of the conceptual models is a criterion of their spreading in the nursing practice in the hospitals of South Bohemian Region. Therefore the research ascertained whether the nurses used some procedures of the conceptual models in their practice. As we can see in Diagram 4, almost $40 \%$ of the nurses stated they use the procedures of conceptual models in practice. The results also show that the use of the procedures of the conceptual models in practice depends on the length of the work experience and the nurses' education. Nurses with shorter practice use them more frequently; the nurses with the longest practice use the procedures less frequently. The nurses who stated they use some procedures from the conceptual models in their practice were further asked whether they consider having sufficient information on the conceptual models in nursing. As we show in diagram No. 5, more than $60 \%$ of nurses consider not having sufficient information on the conceptual models, which seems to be an alarming result. We can observe a connection with the use of the procedures of the conceptual models (Diagram 4 and 5) and lack of information on the conceptual models in nursing. There is a noticeable space here to increase the offer of courses of lifelong education for nurses.

The results presented in Diagram 5 show that most nurses are not sure about the question whether their system of care in their workplace is suitable for nursing documentation according to the conceptual model. As Walsh states, the nurses should be able to assess the system of care at their workplace and to apply a suitable conceptual model when caring the patient. Thus this result is not in 
line with the professional literature (Fitzpatrick and Whall, 1996). As Fitzpatrick and Whall state, a lot of nurses believe that it is more suitable to have one central conceptual model than to use multiple models (Fitzpatrick and Whall, 1996). The results of this research are in line with that. Nurses working at standard wards prefer the possibility to use the conceptual model while nurses from the intensive care units take negative stand more frequently, as we present it in Diagram 6 . This result can be related to the character of work at those wards and to the working habits the nurses have there. The opinion on this issue is also conditioned by the duration of the nurses' work experience. It can be stated, based on the results, that the standpoint to this issue is conditioned by the type of facility and the type of ward the nurses work in. Most nurses prefer the use of one conceptual model within the nursing documentation. Nurses with shorter work experience prefer the use of one conceptual model in nursing documentation more, while nurses with longer work experience more frequently do not have clear opinion on this issue. It was also demonstrated that the use of one conceptual model within the nursing documentation is preferred particularly by nurses with university education. Thus it can be stated that the standpoint to the use of one conceptual model within nursing documentation depends on the duration of work experience and education of the nurses. The research had also formulated the thesis related to the use of multiple conceptual models within nursing documentation. Nurses took stands to this thesis as well, as we show it in Diagram 7. The question was meant as a test question, as it was assumed that nurses who prefer the use of one model would take negative stands to the use of multiple models and vice versa. The results acquired confirmed that assumption. As we show it in Diagram 8, the analysis of the results shows that about $50 \%$ of the nurses expresses their disagreement with the use of multiple conceptual models within nursing documentation. So it was confirmed that those who prefer the use of one conceptual model do not agree with the use of multiple conceptual models and vice versa. Thus it can be stated that the nurses from the hospitals of South Bohemian Region prefer the use of one conceptual model within nursing documentation. Only a minority of the respondents prefers the use of multiple models; but the rate of nurses without a clear opinion on this issue is considerable.

We consider the result interesting; although the nurses report on lack of information on the conceptual models, they predominantly show lack of interest in a possible course on the area of conceptual models, as it can be seen in Diagram 9. 


\section{Conclusion}

The results of the research show that the nurses report on the knowledge of the concept of conceptual model in nursing. Their standpoint to this issue depends on their age, work experience and last but not least on their education. A greater part of nurses state that they rather or definitely encountered some conceptual model in the course of their education. Based on the result of the analysis, it can also be stated that Marjory Gordon's conceptual model is relatively well known among the nurses from the hospitals of South Bohemian Region. Almost 2/5 of the nurses of the hospitals of South Bohemian Region stated that they rather or definitely used some procedures from the conceptual models in their practice. It can be also stated, based on the results, that the nurses from the hospitals of South Bohemian Region prefer the use of one conceptual model within nursing documentation. Only a minority of the respondents prefers the use of multiple models; but the rate of the nurses without a clear opinion on this issue is considerable. The results further show that at present, lack of interest in a possible course on the area of conceptual models prevails among the nurses from the hospitals of South Bohemian Region. Nurses with medium duration of work experience show more interest while nurses with the shortest and the longest work experience in their branch are less interested.

\section{References}

1. ARCHALOUSOVÁ, A., SLEZÁKOVÁ, Z. Aplikace vybraných ošetřovatelských modelů do klinické

2. a komunitní praxe. 1. vyd. HK: Nukleus, 2007. ISBN 80-86225-63-1

3. FARKAŠOVÁ, D. a kol. Ošetřovatelství - teorie. 1. vyd.. Martin: Osveta, 2006. ISBN 80-8063-227-8

4. FITZPATRICK J.J., WHALL, A.L. Conceptual models of nursing: Analysis and application. 3.ed. Stamford: Appleton \& Lange, 1996. ISBN 083-8510647

5. PARKER M. E. Nursing Theories and Nursing Practice. 1.ed. Philadelphia: F. A. Davis Company, 2001.

6. ISBN 080-3606-044

7. PAVLÍKOVÁ, S. Modely ošetřovatelství v kostce. 1.vyd. Praha: Grada, 2006, ISBN 80-247-1211-3

8. RIEHL-SISCA, J., ROY, C. Conceptual models for nursing practice. 3.ed. Norwalk, CT: Appleton \& Lange. 2008, ISBN 083-8512-011 
9. SEDLÁKOVÁ, G., KALÁTOVÁ, D. Vybrané ošetřovatelské modely a týrané dítě. 1.vyd. Praha:Triton. 2011. ISBN 97-8807-3874-124

10. WALSH, M. Models and critical pathways in clinical nursing, 2. ed., Bailliere Tindall, 2007. ISBN 0-7020-2188-1

This article was developed on the basis of the results of the GAJU 079/2010/ project denominated 'Use of the conceptual model and classification systems in nursing documentation, implemented at ZSF JU'.

Pavel Scholz, Valérie Tóthová, František Dolák

University of South Bohemia in České Budějovice, Faculty of Health and Social Studies, Department of Nursing and Midwifery 
